\title{
Dose Response of Endotoxin on Hepatocyte and Muscle Mitochondrial Respiration In Vitro
}

\author{
Victor Jeger, ${ }^{1,2}$ Sebastian Brandt, ${ }^{3}$ Francesca Porta, ${ }^{1}$ Stephan M. Jakob, ${ }^{1}$ \\ Jukka Takala, ${ }^{1}$ and Siamak Djafarzadeh ${ }^{1}$ \\ ${ }^{1}$ Department of Intensive Care Medicine, Inselspital, Bern University Hospital and University of Bern, \\ Freiburgstraße 10, 3010 Bern, Switzerland \\ ${ }^{2}$ Graduate School for Cellular and Biomedical Sciences, University of Bern, Switzerland \\ ${ }^{3}$ Department of Anesthesiology and Pain Therapy, Inselspital, Bern University Hospital and University of Bern, \\ 3010 Bern, Switzerland
}

Correspondence should be addressed to Siamak Djafarzadeh; siamak.djafarzadeh@insel.ch

Received 5 June 2014; Revised 22 August 2014; Accepted 8 September 2014

Academic Editor: Marko Ljubkovic

Copyright (C) 2015 Victor Jeger et al. This is an open access article distributed under the Creative Commons Attribution License, which permits unrestricted use, distribution, and reproduction in any medium, provided the original work is properly cited.

\begin{abstract}
Introduction. Results on mitochondrial dysfunction in sepsis are controversial. We aimed to assess effects of LPS at wide dose and time ranges on hepatocytes and isolated skeletal muscle mitochondria. Methods. Human hepatocellular carcinoma cells (HepG2) were exposed to placebo or LPS $(0.1,1$, and $10 \mu \mathrm{g} / \mathrm{mL})$ for $4,8,16$, and 24 hours and primary human hepatocytes to $1 \mu \mathrm{g} / \mathrm{mL} \mathrm{LPS}$ or placebo $(4,8$, and 16 hours). Mitochondria from porcine skeletal muscle samples were exposed to increasing doses of LPS (0.1$100 \mu \mathrm{g} / \mathrm{mg}$ ) for 2 and 4 hours. Respiration rates of intact and permeabilized cells and isolated mitochondria were measured by high-resolution respirometry. Results. In HepG2 cells, LPS reduced mitochondrial membrane potential and cellular ATP content but did not modify basal respiration. Stimulated complex II respiration was reduced time-dependently using $1 \mu \mathrm{g} / \mathrm{mL}$ LPS. In primary human hepatocytes, stimulated mitochondrial complex II respiration was reduced time-dependently using $1 \mu \mathrm{g} / \mathrm{mL}$ LPS. In isolated porcine skeletal muscle mitochondria, stimulated respiration decreased at high doses (50 and $100 \mu \mathrm{g} / \mathrm{mL}$ LPS). Conclusion. LPS reduced cellular ATP content of HepG2 cells, most likely as a result of the induced decrease in membrane potential. LPS decreased cellular and isolated mitochondrial respiration in a time-dependent, dose-dependent and complex-dependent manner.
\end{abstract}

\section{Introduction}

Endotoxin or lipopolysaccharide (LPS) from the outer membrane of Gram-negative bacteria is a trigger of the systemic inflammatory response in sepsis [1]. Mitochondrial dysfunction has been postulated as a mechanism of cell injury and reduced cellular ATP levels in sepsis [2-5]. Sepsis-induced alterations in mitochondrial respiration may account for the lactate production, intracellular acidosis, generation of toxic radicals, and release of cytochrome $\mathrm{c}$ from damaged mitochondria. A combination of these factors may contribute to multiorgan failure syndrome in sepsis [6-8]. The effects of LPS on mitochondrial function and, specifically, on mitochondrial respiration are controversial.

LPS triggers macrophages via cell surface receptors (mainly TLR-4) to produce powerful inflammatory mediators including tumor necrosis factor-alpha (TNF- $\alpha$ ), interleukin$1 \alpha$ (IL-1 $\alpha)$, IL- $1 \beta$, and IL- 6 . The increased production of these mediators is believed to be the direct cause of LPS toxicity [1,9-11]. Additionally, many studies demonstrated uptake of LPS by cells [12-16]. Recently, LPS was proposed to act intracellularly, independent of Toll-like receptor 4 $[17,18]$. A study on rat cultured hepatocytes demonstrated that LPS binds to the cell membrane and is found afterwards in dispersed localization in the cytoplasm, reaching mitochondria [19]. Consecutively activated caspases might also interact with mitochondria $[20,21]$. In hepatocytes, caspase 1 activation reduced mitochondrial respiration and ROS production by increasing mitochondrial autophagy [22].

Research on the effects of LPS on mitochondria has been confounded by the wide range of doses and exposure times. This has likely contributed to the heterogeneous and 
sometimes contradictory results [23]. Therefore, the aim of the present study was to explore the dose response of LPS on cellular respiration of cultured liver cells and isolated muscle mitochondrial respiration. Hepatocytes were used because (1) liver failure is common in sepsis and (2) intra-abdominal infections are among the main causes of severe sepsis and septic shock [24]; in these circumstances the liver is the first organ to be confronted with (high amounts of) LPS. Muscle mitochondria were used because decreased muscle mitochondrial enzyme activity and ATP content have been reported in sepsis $[25,26]$. We hypothesized that endotoxin alters mitochondrial respiration in a dose-dependent way and differently in liver compared to skeletal muscle tissue.

\section{Materials and Methods}

2.1. Chemicals and Reagents. LPS (TLR4 agonist, ultrapure E. coli K12 lipopolysaccharide) was purchased from InvivoGen (San Diego, CA, USA). All the reagents for cellular respiration were obtained from Sigma-Aldrich (Buchs, Switzerland).

\subsection{Hepatoma Cell Line (HepG2) and Primary Human Hepatocytes}

2.2.1. Cell Culture. Human hepatocellular carcinoma cell line (HepG2, Deutsche Sammlung von Mikroorganismen und Zellkulturen (DSMZ), Braunschweig, Germany, $\mathrm{N}^{\circ}$ ACC 180) was cultured in $25 \mathrm{~cm}^{2}$ flasks (for respiration assays) or 96-well plates (for determination of cellular ATP content and mitochondrial membrane potential) in RPMI 1640 culture medium containing $10 \%$ heat-inactivated fetal calf serum (FCS), $1 \mathrm{mM}$ sodium pyruvate, $0.1 \mathrm{mM}$ nonessential amino acids, $2 \mathrm{mM}$ L-glutamine, 100 units/mL penicillin, and $100 \mathrm{mg} / \mathrm{mL}$ streptomycin at $37^{\circ} \mathrm{C}$ in a humid atmosphere $\left(5 \% \mathrm{CO}_{2}, 95 \%\right.$ air). Cells were passaged upon reaching confluence.

The primary human hepatocytes were kindly provided by D. Stroka (University of Bern). Primary human hepatocytes were isolated from wedges of resected liver tissues taken from patients undergoing liver surgery. Written informed consent was obtained prior to surgery in compliance with the local ethical committee [27]. Cultures from 8 donors were prepared and cultured according to Rencurel et al. [28]. Additional primary human hepatocytes (5 donors) were purchased from ScienCell Research Laboratories (Carlsbad, CA, USA) and incubated with LPS and cell viability and respiration rates of intact cells were analyzed.

2.2.2. Experimental Protocol. Quiescent cells were obtained by total deprivation of FCS for 14 to 16 hours before the experiments. All experiments were performed when cells reached $90-95 \%$ confluency. On the day of experiment, HepG2 was exposed to placebo or LPS $(0.1,1,10 \mu \mathrm{g} / \mathrm{mL})$ for $4,8,16$, and 24 hours. Primary human hepatocytes were exposed to placebo or $1 \mu \mathrm{g} / \mathrm{mL}$ LPS for 4,8 , and 16 hours. At the end of incubation times, cells were removed by trypsinization, permeabilized, and used for mitochondrial respiration. Due to the limited amount of primary human hepatocytes, only 4, 8, and 16 hours of LPS exposure were explored in these cell types.

2.2.3. Determination of Mitochondrial Respiration in Digitonin-Permeabilized Cells. Respiration was determined as described before [29]. After incubation, cells were trypsinized and resuspended in RPMI-1640 with 10\% FBS and then centrifuged for $5 \mathrm{~min}(350 \mathrm{~g})$. Cell number and viability (using the trypan blue method of dead-cell staining) were determined by the Countess automated cell counter (Invitrogen, Eugene, OR, USA). Cells were resuspended in the respiration buffer $(110 \mathrm{mM}$ sucrose, $0.5 \mathrm{mM}$ EGTA, $3.0 \mathrm{mM}$ $\mathrm{MgCl}$, 80 mM KCl, 60 mM K-lactobionate, 10 mM KH2PO4, $20 \mathrm{mM}$ taurine, $20 \mathrm{mM}$ hepes, $1.0 \mathrm{~g} / \mathrm{L} \mathrm{BSA}$, and $\mathrm{pH}$ 7.1.) at a standard concentration of $1 \times 10^{6} \mathrm{cell} / \mathrm{mL}$, and respiration rates were measured at $37^{\circ} \mathrm{C}$ in in $2 \mathrm{~mL}$ glass chambers using the high-resolution oxygraph (Oxygraph-2k, Oroboros Instruments, Innsbruck, Austria). Mitochondrial complex specific respiration rates were assessed by a standard titration protocol: first cells were permeabilized with digitonin $(8.1 \mu \mathrm{M})$ for $5 \mathrm{~min}$. Afterwards, glutamate $(10 \mathrm{mM})$ and malate $(5 \mathrm{mM})$, which provide nicotinamide adenine dinucleotide (NADH) to the respiratory chain, were added (complex I activation), followed by addition of ADP $(0.25 \mathrm{mM})$. After a stable signal was reached and marked, rotenone $(0.5 \mu \mathrm{M})$ was added to inhibit complex I and then complex II-dependent respiration was stimulated by adding succinate $(10 \mathrm{mM})$, which provides flavin adenine dinucleotide (FADH) to the respiratory chain (complex II activation). Afterwards, complex III was inhibited by antimycin A $(0.5 \mu \mathrm{M})$, and complex IV-dependent respiration was measured by adding ascorbate $(4 \mathrm{mM})$ and $\mathrm{N}, \mathrm{N}, \mathrm{N}^{\prime}, \mathrm{N}^{\prime}$-tetramethyl-p-phenylenediamine (TMPD, $0.5 \mathrm{mM}$ ). Since TMPD exhibits a wide range of autooxidation in the buffer, respiration was finally inhibited with sodium azide $(5 \mathrm{mM})$, and the difference between oxygen consumption before and after addition of sodium azide was interpreted as the real complex IV respiration.

2.2.4. Digitonin Titration. To confirm that mitochondrial outer membrane integrity was not compromised in permeabilized cells, we performed digitonin titration to determine the optimal concentration for permeabilization of HepG2 cells and primary human hepatocytes. For these experiments, cells were suspended in respiration buffer $\left(1 \times 10^{6}\right.$ cells $\left./ \mathrm{mL}\right)$ and digitonin concentration was titrated in intact cells by respirometry in the presence of $0.5 \mathrm{mM}$ rotenone (to inhibit endogenous respiration of intact cells), $10 \mathrm{mM}$ succinate, and $1 \mathrm{mM}$ ADP. Respiration rates were measured at baseline and after 2-5 min after each titration. Respiration of intact HepG2 cells and primary hepatocytes was not stimulated in the presence of rotenone, succinate, and ADP. However subsequent stepwise digitonin titration yielded gradual permeabilization of plasma membranes, shown by the increase of respiration up to full permeabilization. Permeabilization at a digitonin concentration of $8-10 \mu \mathrm{M}$ was optimum for ADP-stimulated respiration. 
2.2.5. Coupled and Uncoupled Respiration of Intact Cells: Cellular Respiration. After incubation with LPS (HepG2: $1 \mu \mathrm{g} / \mathrm{mL}, 24$ hours; primary human hepatocytes: $1 \mu \mathrm{g} / \mathrm{mL}, 24$ hours), cells were trypsinised and resuspended in RPMI1640 with 10\% FBS and then centrifuged for $5 \mathrm{~min}(350 \mathrm{~g})$. Cells were resuspended in the respiration buffer $(110 \mathrm{mM}$ sucrose, $0.5 \mathrm{mM}$ EGTA, $3.0 \mathrm{mM} \mathrm{MgCl} 2,80 \mathrm{mM} \mathrm{KCl}, 60 \mathrm{mM}$ K-lactobionate, $10 \mathrm{mM}$ KH2PO4, $20 \mathrm{mM}$ taurine, $20 \mathrm{mM}$ hepes, $1.0 \mathrm{~g} / \mathrm{L} \mathrm{BSA}$, and $\mathrm{pH} 7.1$ ) at a concentration of $1 \times$ $10^{6}$ cells $/ \mathrm{mL}$. Respiration rates were measured at $37^{\circ} \mathrm{C}$ using a high-resolution oxygraph (Oxygraph-2k, Oroboros Instruments, Innsbruck, Austria). Basal coupled endogenous respiration of intact cells (oxygen consumption without the addition of exogenous substrate) was measured and recorded using the linear rate of oxygen consumption. Afterwards, oligomycin (an inhibitor of ATP synthase) $(0.4 \mu \mathrm{g} / \mathrm{mL}$ ) was added and the nonphosphorylating respiration rate was measured (oligomycin-insensitive respiration). Afterwards the chemical uncoupler FCCP (carbonyl cyanide ptrifluoromethoxyphenylhydrazone) was sequentially added at different concentrations $(0.1$ to $0.5 \mu \mathrm{M})$ and maximal uncoupled respiration was recorded. Thereafter, respiration was inhibited with the addition of rotenone $(0.5 \mu \mathrm{M})$ and antimycin $\mathrm{A}(0.5 \mu \mathrm{M})$ and the remaining background respiration was subtracted from all results. The uncoupled respiratory control ratio (uRCR) was calculated as the ratio between the oxygen consumption rate in the presence of FCCP and the rate in the presence of oligomycin. The oligomycin-sensitive respiration (ATP turnover) was calculated by subtracting the oligomycin-insensitive respiration from basal endogenous respiration. The coupling efficiency corresponded to the ratio of oligomycin-sensitive respiration rates by basal respiration rates.

2.2.6. Measurement of Mitochondrial Membrane Potential in Intact Cells. The mitochondrial electrochemical potential gradient $(\Delta \psi \mathrm{m})$ in intact cells was measured using the cationic dye 5,5', $6^{\prime}, 6^{\prime}$-tetrachloro-1,1',3,3' -tetraethylbenzimidazolo-carbocyanine iodide (JC-1). JC-1 is a mitochondrial sensor which aggregates in polarized mitochondria, where it forms red fluorescent aggregates. Dissipation of the mitochondrial membrane potential prevents the accumulation of the JC-1 dye in the mitochondria, and the dye is dispersed throughout the entire cell, leading to a shift from red (JC1 aggregates) to green fluorescence (JC-1 monomers). Thus the loss of JC-1 aggregates directly correlates with changes in $\Delta \psi \mathrm{m}$. Briefly, for these experiments, the cells were grown in 96 -well plates and treated with LPS for 24 hours $(1 \mu \mathrm{g} / \mathrm{mL})$ and the mitochondrial membrane potential was measured using the JC-1 mitochondria staining kit for mitochondrial potential change detection (Sigma, Switzerland) according to the manufacturer's instructions. $\Delta \psi \mathrm{m}$ was measured immediately by fluorimetry. For JC-1 monomers, the fluorimeter was set at a $490 \mathrm{~nm}$ excitation wavelength and $530 \mathrm{~nm}$ emission wavelength and fluorescence was measured. For JC1 aggregates, the fluorimeter was set at a $525 \mathrm{~nm}$ excitation wavelength and $590 \mathrm{~nm}$ emission wavelength and fluorescence was measured. Afterwards, the $\Delta \psi \mathrm{m}(590 / 530 \mathrm{~nm}$ fluorescence ratio) was calculated. Valinomycin $(2.5 \mu \mathrm{g} / \mathrm{mL})$ was used as a positive control to depolarize the mitochondrial membrane potential.

2.2.7. Cytochrome $c$ Test. In some additional experiments, to evaluate the quality of the mitochondria, cytochrome c test was performed to verify outer mitochondrial membrane integrity. For these experiments, HepG2 and primary human hepatocytes were incubated with LPS and permeabilized with digitonin $(8.1 \mu \mathrm{M})$ and mitochondrial outer membrane integrity was tested by measurement of mitochondrial respiration after the subsequent additions of glutamate $(10 \mathrm{mM})$ and malate $(5 \mathrm{mM})$ and/or succinate $(10 \mathrm{mM}), \mathrm{ADP}$ $(0.25 \mathrm{mM})$, and cytochrome $\mathrm{c}(10 \mu \mathrm{M})$ followed by the addition of oligomycin $(0.4 \mu \mathrm{g} / \mathrm{mL})$ to mimic state 4 .

2.2.8. Measurement of the HepG2 Cells ATP Content. For these experiments, the cells were grown in 96-well plates and treated with LPS for 24 hours $(1 \mu \mathrm{g} / \mathrm{mL})$. After treatment, cells were lysed and exposed to the ATP substrate solution using the Luminescent ATP Detection Assay Kit (Abcam, Cambridge, USA) according to the manufacturer's instructions and signal was measured on a luminescent counter. The assay kit is a cellular ATP monitoring system based on firefly (Photinus pyralis) luciferase and is based on the production of light caused by the reaction of ATP with added luciferase and D-luciferin. The emitted light is proportional to the ATP concentration inside the cell. Valinomycin $(2.5 \mu \mathrm{g} / \mathrm{mL})$ was added to assess the effect of depolarized mitochondrial membrane potential on ATP content.

2.2.9. Measurement of Release of Reactive Oxygen Species (ROS) and Reactive Nitrogen Species (RNS). Cells were grown in 96-well plates and treated with LPS for 24 hours $(1 \mu \mathrm{g} / \mathrm{mL})$. Total free radicals (ROS and RNS) levels were measured in the supernatant using the OxiSelect In Vitro ROS/RNS Assay Kit (Cell Biolabs Inc., San Diego, CA, USA). ROS and RNS species react with DCFH to the fluorescent $2^{\prime}, 7^{\prime}$ dichlorodihydrofluorescein (DCF). Its fluorescence intensity is proportional to the total ROS and RNS levels within the sample and was measured by fluorimetry.

\subsection{Skeletal Muscle Mitochondria}

2.3.1. Mitochondrial Isolation. Quadriceps muscle biopsy was taken from 7 anaesthetized pigs, from which mitochondria were isolated by differential centrifugation as described by Porta et al. [30]. Protein concentration was determined using the Quant-itTM Protein Assay kit and read in QubitTM fluorometer (Invitrogen, Basel, Switzerland). Pigs were used afterwards for another experiment. The study was performed in accordance with the National Institutes of Health guidelines for the care and use of experimental animals and with the approval of the Animal Care Committee of the Canton Bern, Switzerland.

2.3.2. Experimental Protocol. The protocol started immediately after isolation of the mitochondria, and determination of respiration was finished within 6 hours in all groups. Mitochondria from each biopsy sample were divided into 12 


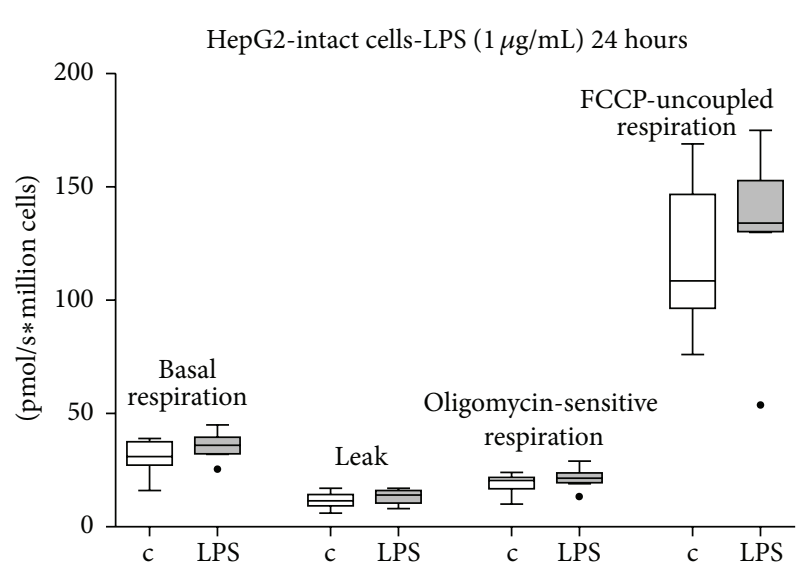

(a)

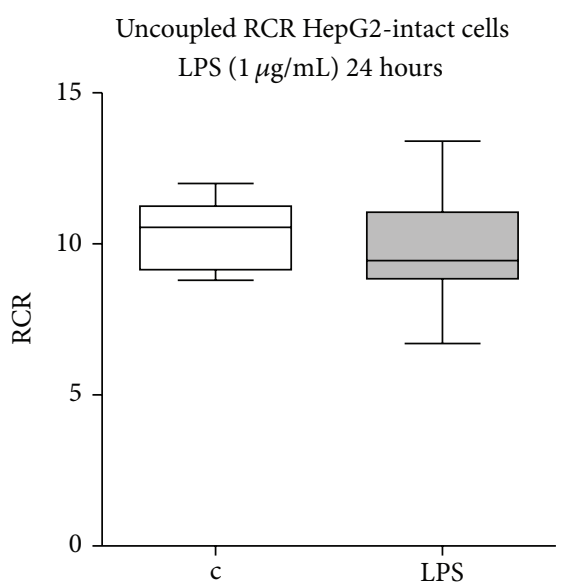

(b)

Coupling efficiency HepG2-intact cells

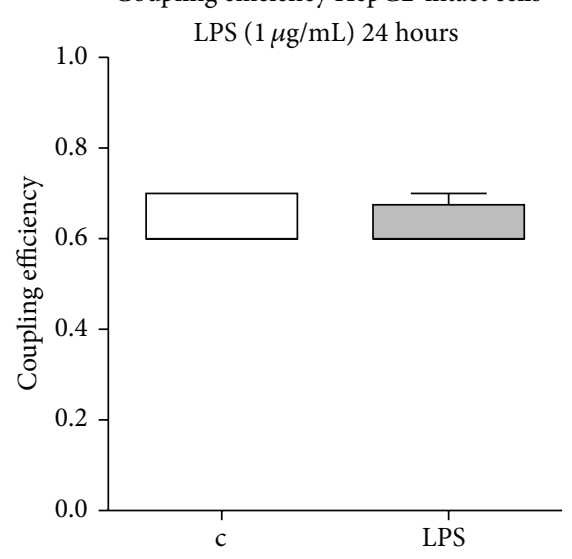

(c)

FIGURE 1: Basal respiration of intact cells. HepG2 cells' basal oxygen consumption, in the presence of oligomycin (leak respiration), and FCCP, respectively, in LPS treated and control cells ( $(\mathrm{a}) ; n=8$ each). The uncoupled respiratory control ratio (uRCR) was calculated as the ratio between the oxygen consumption rate in the presence of FCCP and the rate in the presence of oligomycin (b) and the coupling efficiency was calculated as the ratio between oligomycin-sensitive and basal respiration rates (c). Data represented as box and whiskers (Tukey). Statistical significance between samples was assessed using a Wilcoxon test. c: control; LPS: $1 \mu \mathrm{g} / \mathrm{mL}$ LPS for 24 hours.

groups and incubated on ice with vehicle or $0.1,1,10,50$, and $100 \mu \mathrm{g}$ LPS/mg mitochondrial protein both for 2 hours and for 4 hours. The different concentrations at 2 or 4 hours were assessed in a randomized fashion. The data were compared with its time-matched controls to prevent a time effect due to a longer delay after isolation.

\subsubsection{Determination of Mitochondrial Respiration in Isolated} Mitochondria. Mitochondrial respiration was performed as described before [31]. Respiratory rates were determined at a final mitochondrial protein concentration of $0.4 \mathrm{mg} / \mathrm{mL}$ in the above-described respiration buffer. Respiration was measured at $37^{\circ} \mathrm{C}$ in $2 \mathrm{~mL}$ glass chambers using the high-resolution oxygraph (Oxygraph-2k, Oroboros Instruments, Innsbruck, Austria). Each complex was assessed with a separate mitochondrial sample. Maximal oxidative capacities (state 3) were determined in the presence of oxygen content of room air (21\%). For complex I-dependent respiration, substrates were glutamate $(10 \mathrm{mM})+$ malate $(5 \mathrm{mM})$ followed by ADP
$(0.025 \mathrm{mM})$. For measurement of complex II-dependent respiration, succinate $(10 \mathrm{mM})$ and $\operatorname{ADP}(0.025 \mathrm{mM})$ were added. The coupling of phosphorylation to oxidation was determined by calculating the respiratory control ratio (RCR) as the ratio between ADP-stimulated respiration (state 3) and respiration after ADP depletion (state 4). Complex IV-dependent respiration was measured by adding ascorbate $(4 \mathrm{mM}), \mathrm{N}, \mathrm{N}, \mathrm{N}^{\prime}, \mathrm{N}^{\prime}$-tetramethyl-p-phenylenediamine (TMPD, $0.5 \mathrm{mM})$ and ADP $(0.025 \mathrm{mM})$. Since TMPD exhibits a wide range of autooxidation in the buffer, respiration was finally inhibited with sodium azide $(5 \mathrm{mM})$, and the difference between the oxygen consumption before and after the addition of sodium azide was interpreted as the real complex IV respiration. Respiration rates were calculated as the time derivative of oxygen concentration measured in the closed respirometer and expressed per million viable cells. The amplified signal was recorded in a computer with online display of the calibrated oxygen concentration and oxygen flux (DatLab software for data acquisition and 


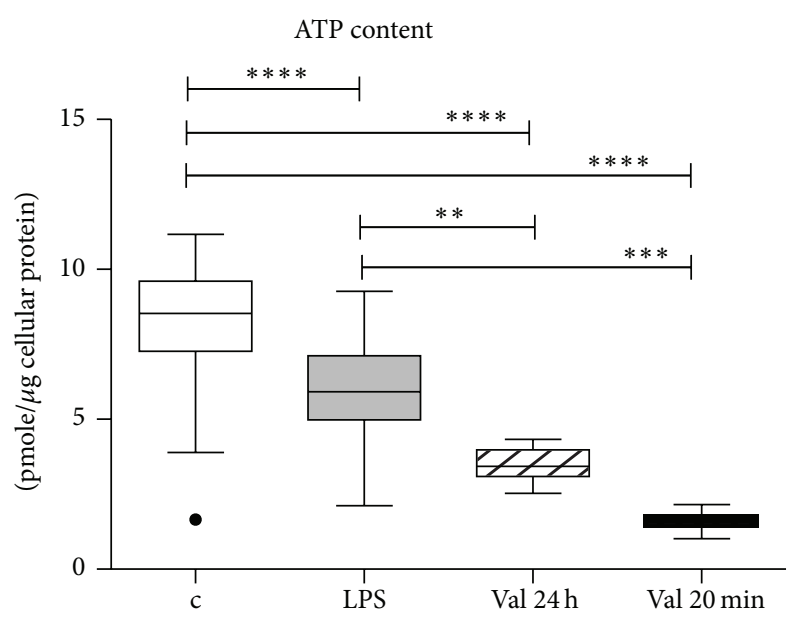

(a)

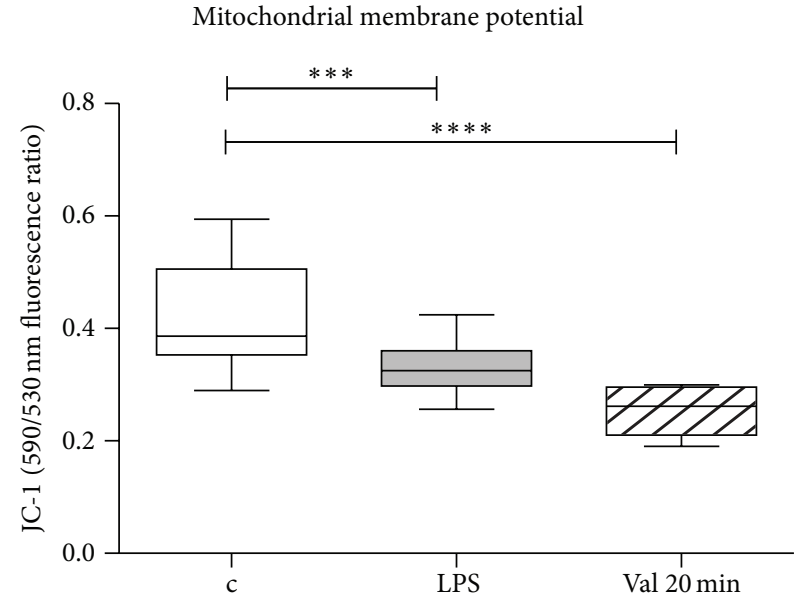

(b)

FIGURE 2: ATP content and mitochondrial membrane potential of intact cells. (a) Cellular ATP content of HepG2 was determined after 24 hours exposure with $1 \mu \mathrm{g} / \mathrm{mL}$ LPS $(n=90)$, control $(n=102)$, valinomycin $(2.5 \mu \mathrm{g} / \mathrm{mL})$ for $24 \mathrm{~h}(n=12)$, and valinomycin for $20 \mathrm{minutes}(n=$ 12). Kruskal-Wallis $P<0.0001$. (b) Mitochondrial membrane potential measured by the changes in the $590 / 530$ JC-1 emitted fluorescence. Control: $n=30$, LPS: $n=24$. Valinomycin $(2.5 \mu \mathrm{g} / \mathrm{mL}$; incubation for 20 minutes $)$ served as a positive control, to depolarize mitochondrial membrane potential $(n=6)$. Data are represented as box and whiskers (Tukey). Groups were compared using Mann-Whitney $U$ test (two groups) or Kruskal-Wallis test followed by Dunn's correction of multiple comparisons (three groups). (c: control; LPS: lipopolysaccharide; val: valinomycin.)

analysis; Oroboros Instruments, Innsbruck, Austria). Oxygen consumption is expressed as $\mathrm{pmol} \mathrm{O}_{2} / \mathrm{s} / \mathrm{mg}$ of mitochondrial protein.

2.4. Statistics. Statistical analysis was performed with the SPSS software package (SPSS 15.0, SPSS Inc., Chicago, IL) and Prism 6 (GraphPad Software, La Jolla, CA). Mitochondrial respiration of each complex at different doses of LPS was compared at each time point using the nonparametric Friedman test followed by the Dunn's test for multiple comparisons. If significant, the Wilcoxon test was used to compare this dose with its control. For primary human hepatocytes, the Wilcoxon test was used as only one dose of LPS was explored, due to the limited availability of primary human hepatocytes. For unpaired data (ATP content, mitochondrial membrane potential) the Mann-Whitney test was used. Data are shown as median and interquartile range (IQR).

\section{Results}

3.1. Hepatoma Cell Line (HepG2). For the measurement of cellular respiration of intact cells, cells were exposed to LPS and respiration rates were measured in the absence of exogenous substrates and ADP. LPS at $1 \mu \mathrm{g} / \mathrm{mL}$ for 24 hours did not affect basal endogenous cellular respiration of intact cells, oligomycin-insensitive (nonphosphorylating respiration), oligomycin-sensitive (ATP turnover), and FCCPuncoupled maximal respiration rates (Figure 1(a)). Neither uncoupled respiratory control ratio (the ratio between FCCP and oligomycin-insensitive respiration rates) nor coupling efficiency (the ratio between oligomycin-sensitive and basal respiration rates) were affected (Figure $1(\mathrm{~b})$ ). LPS did not affect cellular viability (median, IQR: $89 \%$ (85\%-90\%) live cells in controls versus $88 \%$ (86\%-90\%), in stimulated cells).
LPS at $1 \mu \mathrm{g} / \mathrm{mL}$ for 24 hours decreased cellular ATP content and mitochondrial membrane potential in intact cells (Figure 2). Valinomycin, which was used as a positive control and is known to depolarize mitochondrial membrane potential, did induce a significant decrease in mitochondrial membrane potential and cellular ATP content (Figure 2). LPS did not alter reactive oxygen species (ROS) and reactive nitrogen species (RNS) concentration in the cell culture medium (Figure 3).

Representative respiration rates of permeabilized HepG2 cells using high-resolution respirometry are shown in Figure 4 ( $n=10$ for each experiment). 24 hours of incubation with LPS $(1 \mu \mathrm{g} / \mathrm{mL})$ induced a significant reduction in maximal complex II-dependent and IV-dependent respiration of HepG2 cells but did not affect cell viability (Table 1). 0.1 and $10 \mu \mathrm{g} \mathrm{LPS} / \mathrm{mL}$ as well as 4,8 , and 16 hours of incubation induced no significant changes.

3.2. Isolated Primary Human Hepatocytes. Basal respiration rates were determined in intact primary human hepatocytes in the absence of exogenous substrates (Figure 5). There were no significant differences after exposure to $1 \mu \mathrm{g} / \mathrm{mL}$ LPS (8 hours incubation).

$1 \mu \mathrm{g} / \mathrm{mL}$ LPS reduced complex II-dependent but not complex I-dependent or complex IV-dependent respiration of isolated and permeabilized human hepatocytes after 8 hours incubation $(P=0.016$; Table 2$)$. LPS did not affect viability of isolated primary human hepatocytes (Table 2).

3.2.1. Cytochrome c. Cytochrome c did not enhance respiration of the HepG2 or primary human hepatocytes treated with placebo or LPS indicating that there was no loss of 


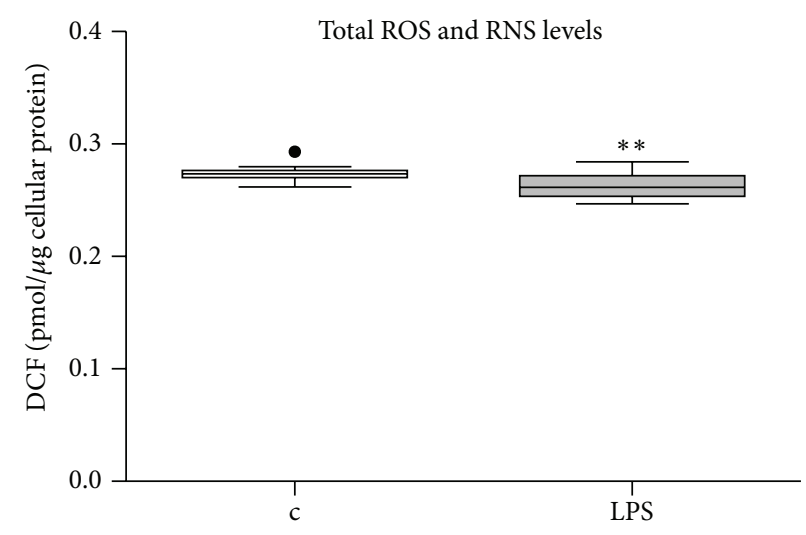

FIGURE 3: Measurements of total free radical ROS and RNS levels in supernatants of intact cells. Total reactive oxygen species (ROS) and reactive nitrogen species (RNS) were determined after reaction with DCFH to DCF $\left(2^{\prime}, 7^{\prime}\right.$-dichlorodihydrofluorescein) in supernatants of LPS treated and control cells $(N=16$ each). The fluorescence of DCF is proportional to the content of ROS and RNS in the cell culture medium. DCF was expressed per pmol DCF/ $\mu$ g cellular protein. Data are represented as box and whiskers (Tukey). Groups were compared using Mann-Whitney $U$ test. ${ }^{* *} P=0.0052$.
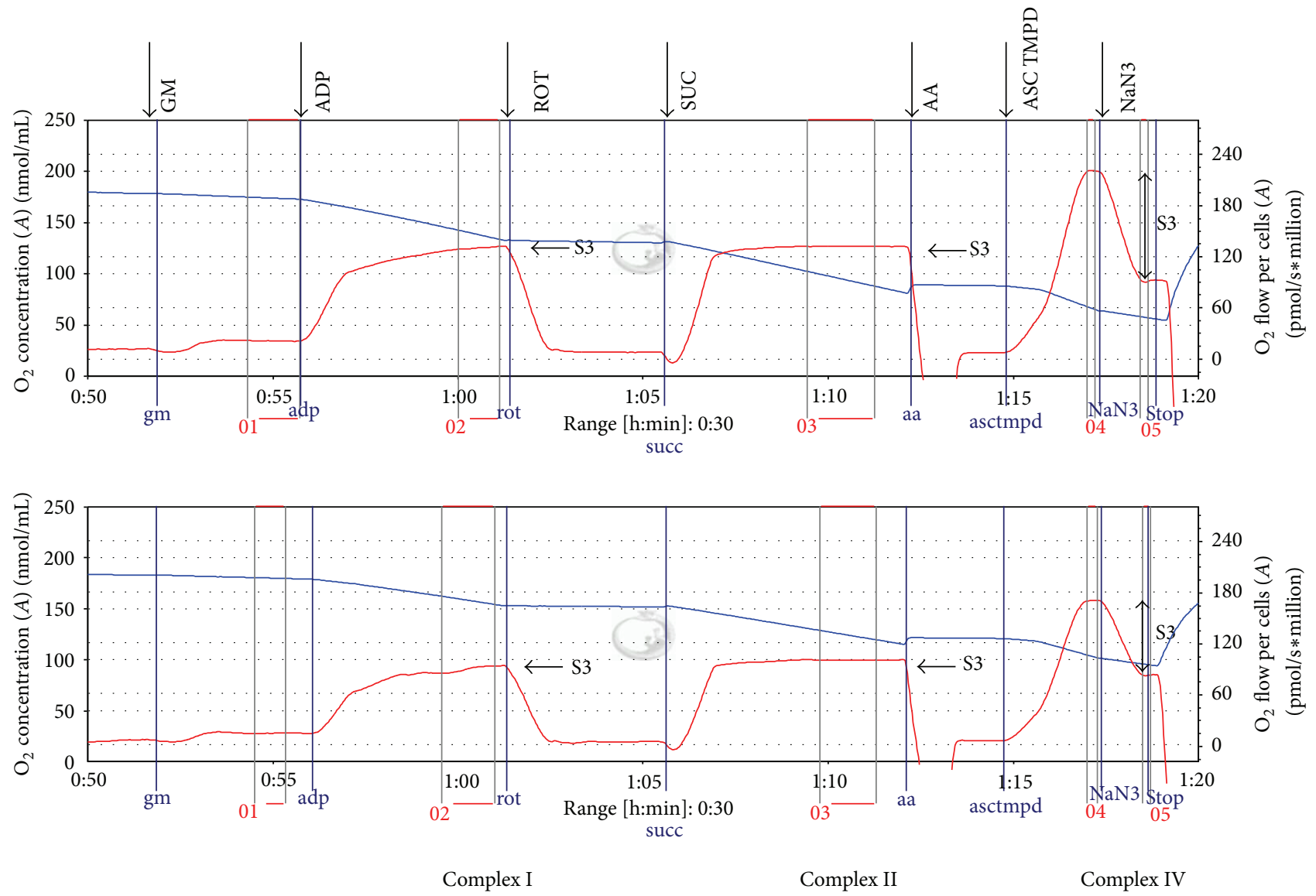

FIGURE 4: Tracings from the OROBOROS-high-resolution respirometry of permeabilized cells. Legend: the upper tracing represents a cell sample incubated with placebo (control) for 24 hours; the lower tracing represents a cell sample at the same passage number incubated with $1 \mu \mathrm{g} / \mathrm{mL}$ LPS for 24 hours. The experiments were recorded simultaneously. The blue line represents oxygen concentration; the red line represents the oxygen flow (slope of oxgygen concentration). GM: Glutamate + malate, ADP: adenosine diphosphate, ROT: rotenone, SUC: succinate, AA: antimycin A, ASC TMPD: ascorbate $+\mathrm{N}, \mathrm{N}, \mathrm{N}^{\prime}, \mathrm{N}^{\prime}$-tetramethyl-p-phenylenediamine, $\mathrm{NaN}_{3}$ : sodium azide, and S3: state 3. State 4 cannot be measured due to the saturating concentration of ADP during the experiment. 
TABLE 1: Effects of LPS exposure on cellular respiration and cell viability of cultured, digitonin-permeabilized human hepatoma cells (HepG2) for various time intervals and at different concentrations. For cellular respiration, all values are expressed as pmol $\mathrm{O}_{2} /(\mathrm{sec} * \mathrm{Mill}$. Cells); ${ }^{* *} P<0.01 ; n=10$ each (LPS treated and control cells); data are expressed as median (IQR). Friedman test followed by Dunn's correction of mutliple comparisons was used to detect differences between doses of LPS at each time point. If significant, a Wilcoxon test was used to compare the difference compared to the corresponding control group. Wilcoxon of complex II 24 hours $1 \mu \mathrm{g}$ LPS/mL versus control: $P=$ 0.002; Wilcoxon of complex IV 24 hours $1 \mu \mathrm{g}$ LPS/mL versus control: $P=0.004$.

\begin{tabular}{|c|c|c|c|c|c|c|}
\hline HepG2 permeabilized & & Control & $0.1 \mu \mathrm{g}$ LPS $/ \mathrm{mL}$ & $1 \mu \mathrm{g}$ LPS/mL & $10 \mu \mathrm{g} \mathrm{LPS} / \mathrm{mL}$ & Friedman $P$ \\
\hline \multirow{4}{*}{ Complex I } & $4 \mathrm{~h}$ & $99(86-112)$ & $107(88-115)$ & 105 (101-111) & $106(98-119)$ & 0.430 \\
\hline & $8 \mathrm{~h}$ & $90(78-99)$ & $89(77-105)$ & $89(82-96)$ & $88(76-95)$ & 0.392 \\
\hline & $16 \mathrm{~h}$ & $95(68-101)$ & $96(83-106)$ & $95(84-101)$ & 89 (81-99) & 0.472 \\
\hline & $24 \mathrm{~h}$ & $96(82-110)$ & $105(92-111)$ & $87(84-97)$ & $91(77-110)$ & 0.339 \\
\hline \multirow{4}{*}{ Complex II } & $4 \mathrm{~h}$ & $121(107-126)$ & $115(108-134)$ & $123(109-127)$ & $124(114-130)$ & 0.516 \\
\hline & $8 \mathrm{~h}$ & $126(109-135)$ & $117(95-133)$ & $131(118-145)$ & $125(99-135)$ & 0.339 \\
\hline & $16 \mathrm{~h}$ & $104(81-129)$ & $120(91-132)$ & $115(95-126)$ & $108(95-126)$ & 0.669 \\
\hline & $24 \mathrm{~h}$ & $94(78-111)$ & $94(84-105)$ & ${ }^{* *} 76(68-93)$ & $84(67-99)$ & 0.006 \\
\hline \multirow{4}{*}{ Complex IV } & $4 \mathrm{~h}$ & $172(166-187)$ & $179(155-210)$ & $170(166-181)$ & $174(161-185)$ & 0.669 \\
\hline & $8 \mathrm{~h}$ & $166(97-200)$ & $144(118-166)$ & $145(126-168)$ & $147(129-173)$ & 0.840 \\
\hline & $16 \mathrm{~h}$ & $139(90-171)$ & $127(108-165)$ & $123(111-156)$ & $122(109-174)$ & 0.840 \\
\hline & $24 \mathrm{~h}$ & $98(90-130)$ & $99(84-118)$ & ${ }^{* *} 81(63-93)$ & $98(89-133)$ & 0.007 \\
\hline \multirow{3}{*}{ Viability (\%) } & $8 \mathrm{~h}$ & $84(68-91)$ & $87(72-95)$ & 88 (71-93) & $88(70-92)$ & \\
\hline & $16 \mathrm{~h}$ & $95(93-96)$ & $93(90-94)$ & 94 (91-95) & 94 (90-95) & \\
\hline & $24 \mathrm{~h}$ & $94(92-95)$ & $92(89-93)$ & $94(93-95)$ & 93 (90-95) & \\
\hline
\end{tabular}

TABLE 2: Time course of $1 \mu \mathrm{g} / \mathrm{mL}$ LPS on oxygen consumption and cell viability of isolated and permeabilized human hepatocytes. 8 hours of incubation with $1 \mu \mathrm{g} / \mathrm{mL}$ LPS reduces complex II-dependent respiration compared to control $\left({ }^{*} P=0.03\right)$. For cellular oxygen consumption, all values are expressed as $\mathrm{pmol} \mathrm{O}_{2} /(\mathrm{sec} *$ Mill. Cells). A Wilcoxon test for non-parametric paired data was used to compare the control group with the LPS group at each time point. $N=8$ for 4 and 16 hours, $n=7$ for 8 hours in LPS treated and control cells.

\begin{tabular}{|c|c|c|c|c|c|}
\hline Primary hepatocytes permeabilized & & Control & $1 \mu \mathrm{g} \mathrm{LPS} / \mathrm{mL}$ & $n$ & $P$ \\
\hline \multirow{3}{*}{ Complex I } & $4 \mathrm{~h}$ & $252(91-351)$ & $287(116-337)$ & 8 & 0.547 \\
\hline & $8 \mathrm{~h}$ & $248(93-340)$ & $198(88-293)$ & 7 & 0.156 \\
\hline & $16 \mathrm{~h}$ & $191(112-368)$ & $172(113-329)$ & 8 & 0.641 \\
\hline \multirow{3}{*}{ Complex II } & $4 \mathrm{~h}$ & $411(198-474)$ & $342(201-510)$ & 8 & 0.844 \\
\hline & $8 \mathrm{~h}$ & $454(242-523)$ & ${ }^{*} 365(167-511)$ & 7 & 0.016 \\
\hline & $16 \mathrm{~h}$ & $317(239-530)$ & $274(241-516)$ & 8 & 0.742 \\
\hline \multirow{3}{*}{ Complex IV } & $4 \mathrm{~h}$ & $242(192-308)$ & $256(146-346)$ & 8 & 0.641 \\
\hline & $8 \mathrm{~h}$ & $257(167-350)$ & $203(143-383)$ & 7 & 0.375 \\
\hline & $16 \mathrm{~h}$ & $287(208-362)$ & $308(179-388)$ & 8 & 0.844 \\
\hline \multirow{4}{*}{ Viability (\%) } & control & $98(93-99)$ & & 5 & \\
\hline & $4 \mathrm{~h}$ & & $91(83-95)$ & 5 & \\
\hline & $8 \mathrm{~h}$ & & $99(99-100)$ & 5 & \\
\hline & $16 \mathrm{~h}$ & & 97 (93-99) & 5 & \\
\hline
\end{tabular}

cytochrome c from mitochondrial outer membrane and mitochondrial integrity was preserved (data not shown).

3.3. Isolated Mitochondria. Control mitochondria kept on ice for 4 hours were significantly lower compared to the same mitochondria analyzed 2 hours after isolation. To prevent the time effect, each exposed sample of mitochondria was compared to its time-matched control sample. Two-hour incubation with 50 and $100 \mu \mathrm{g}$ LPS/mg mitochondrial protein reduced complex I state 3 , complex I state 4 , and complex II state 3 dependent mitochondrial oxygen consumption (Table $3)$.

\section{Discussion}

LPS did not impair basal respiration in intact HepG2 cells. Despite maintained oxygen consumption, cellular ATP content was reduced, likely as a result of the induced reduction of the mitochondrial membrane potential. The effects were similar, albeit less strong, than those of valinomycin, an 


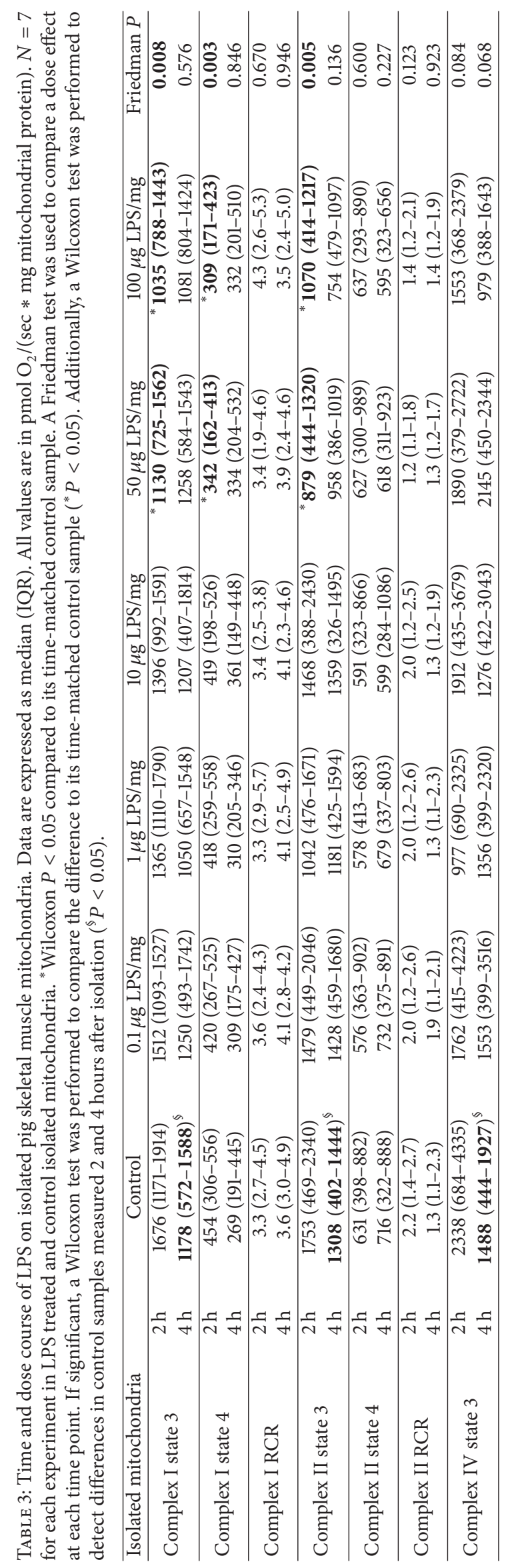




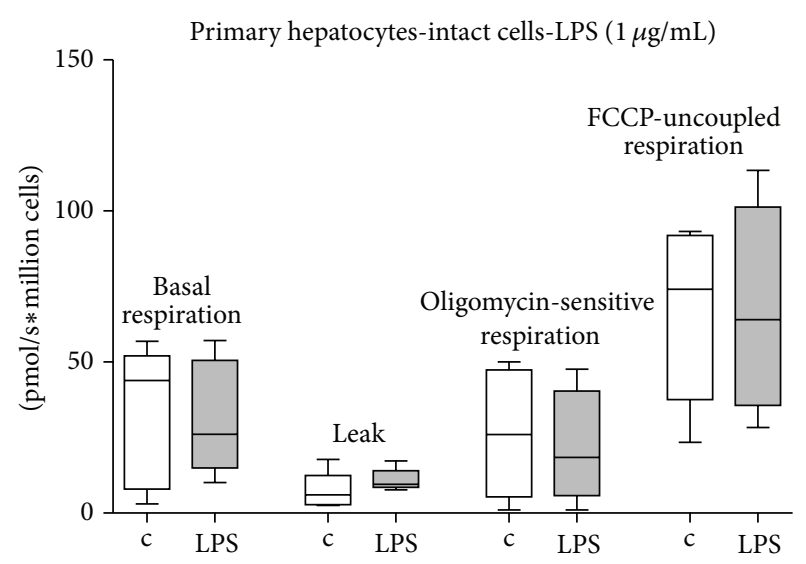

(a)

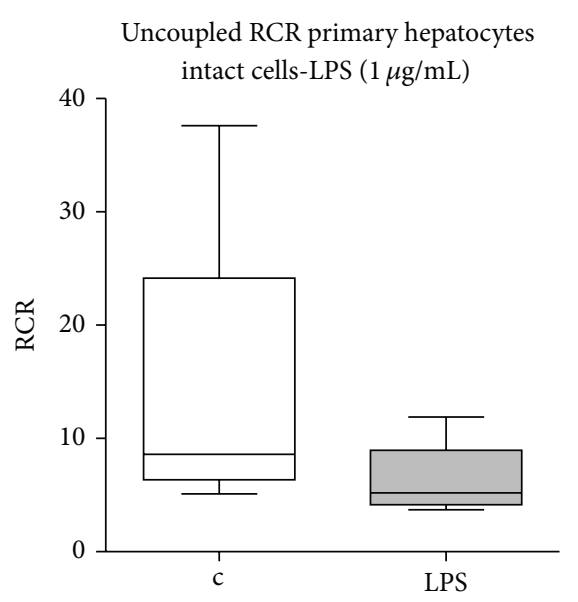

(b)

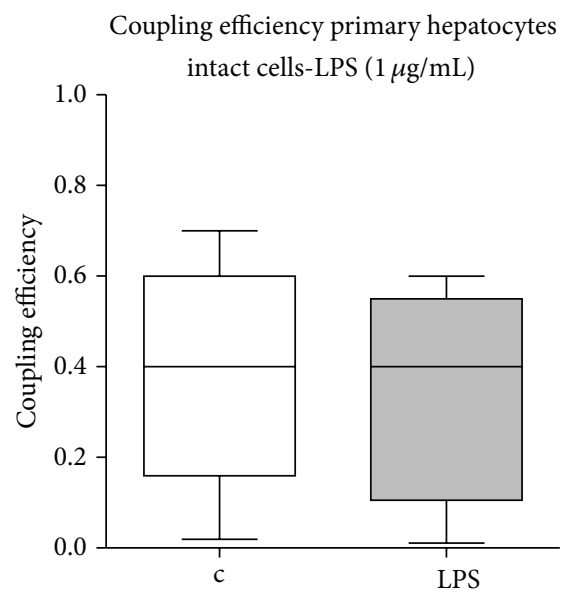

(c)

FIGURE 5: Basal respiration of intact cells. Primary human hepatocytes' basal oxygen consumption, in the presence of oligomycin (leak respiration), and FCCP, respectively, in LPS treated and control cells ((a); $n=5$ each). The uncoupled respiratory control ratio (uRCR) was calculated as the ratio between the oxygen consumption rate in the presence of FCCP and the rate in the presence of oligomycin (b) and the coupling efficiency was calculated as the ratio between oligomycin-sensitive and basal respiration rates (c). Data represented as box and whiskers. Statistical significance between samples was assessed using a Wilcoxon test. c: control; lps: $1 \mu \mathrm{g} / \mathrm{mL}$ LPS for 8 hours.

ionophore capable of depolarizing mitochondria [32]. Others confirmed the mitochondrial potential lowering characteristics of LPS in hepatocytes [33-35]. LPS may cause recruitment of an uncoupling protein (UCP2) both in vivo and in vitro and thereby decrease the mitochondrial membrane potential [34]. LPS can also induce ROS production and loss of mitochondrial membrane potential by TNF- $\alpha$ and IFN- $\gamma$ upregulation via iNOS induction and NO production [35].

Mitochondrial oxygen consumption was only affected by LPS when respiration was stimulated with complex specific substrates (e.g., succinate for complex II). In primary human hepatocytes LPS induced a reduction in complex II-dependent respiration rates. Due to the limited availability of primary human hepatocytes, we evaluated further effects of LPS in HepG2 cells, a human hepatoma cell line. Also in HepG2 cells, LPS reduced stimulated respiration. Finally, maximal respiration was also impaired in isolated skeletal muscle mitochondria.
Our data confirm the findings of a previous review on effects of sepsis on mitochondrial functions and may explain the heterogenous results in the literature: LPS effects seem to be time, dose, tissue, and method dependent. We found impaired respiration after $8 \mathrm{hrs}$ (human hepatocytes) or only after $24 \mathrm{hrs}$ of LPS incubation (HepG2 cells) and at $1 \mu \mathrm{g}$ LPS/mL (hepatocytes) or at only 50 and $100 \mu \mathrm{g}$ LPS/mL (isolated skeletal mitochondria). Furthermore, mitochondrial complexes I, II, or IV could be implicated alone or in various combinations. Finally, we demonstrate that immediate processing of tissue samples is crucial for detection of LPS effects. This is especially important when time-consuming procedures like differential centrifugation are involved.

Transient effects of LPS on primary hepatocytes' mitochondrial respiration have been reported previously [33]. In a former experimental series, we have also reported transient effects of TLR-3 stimulation on HepG2 and postulated mitochondrial biogenesis to be involved in mitochondrial 
recovery [29]. New insights to this phenomenon come from a recently published article: it was proposed that, in reaction to LPS or sepsis, mitochondrial oxygen consumption is reduced as a protective mechanism to prevent cell death [33]. During recovery, the cell may get rid of dysfunctional mitochondria by autophagy and seems to activate mitochondrial biogenesis via TLR-9 stimulation in autophagosomes, which could lead finally to a restored function of mitochondria [33].

LPS is recognized by TLR4, which is present not only on the surface of immune cells but also on the surface of hepatocytes [1, 36, 37], including HepG2 cells [38, 39]. However, their density on the cell surface may vary. The binding of LPS on TLR4 activates complex intracellular pathways leading to the activation of transcription factors like $N F \kappa B$, which then results in the release of mediators of the immune system [40]. TLR1/2/4 signaling drives mitochondria in macrophages to increase reactive oxygen species (ROS) production in response to bacteria [41]. West et al. suggested a direct signaling pathway that links TLR's with mitochondria [41]. In HepG2 cells in the present study ROS and RNS levels were not increased after $24 \mathrm{~h}$ exposure to LPS. It has been described that the increase in ROS is transient [42], and we may have missed the peak in our study.

In addition to a TLR4 mediated pathway, a mechanism of LPS endocytosis is postulated and it has been shown that LPS can reach mitochondria directly $[12-16,19]$. Therefore, we evaluated the effect of increasing LPS doses at different exposure times on isolated skeletal muscle mitochondria from healthy pigs. We observed impaired mitochondrial respiration only at high LPS doses. We did not observe any effect on respiratory control ratio (RCR) of isolated muscle mitochondria because of the simultaneous decrease of state 3 and state 4 . However, others found a reduced RCR after exposure of isolated mitochondria to LPS, either by a decrease in state 3 or by an increase in state $4[43,44]$. The mechanism of a direct LPS effect on mitochondria is not well understood. Recently, TLR-4 independent activation of caspase 11 by intracellular LPS was proposed, which could lead to either IL1 activation or cell death $[17,18]$. The intermediates or receptors for intracellular LPS are not known. Furthermore, there are reports about intracellular TLR4 receptors in macrophages and human coronary artery endothelia cells, which react to LPS stimuli $[45,46]$. But till now, there is no evidence of any interaction of intracellular TLR4 and mitochondria. Therefore, it is not known how LPS induces isolated mitochondrial dysfunction directly.

In HepG2 and primary human hepatocytes, LPS decreased cellular respiration in the presence of exogenous substrates (permeabilized cells) without impairing basal respiration of intact cells. A limitation of the present study is that most of the cellular experiments were performed in HepG2 cells, due to the limited availability of primary human hepatocytes. HepG2, a human hepatoma cell line, has a different phenotype compared to primary hepatocytes and is thought to be a mature epithelial cell line, which can form structures similar to bile canaliculi [47]. HepG2 has a lower rate of triglycerides secretion than primary hepatocytes and resembles more fasted primary hepatocytes [47]. Furthermore, HepG2 has very low levels of functional cytochrome
P450 enzymes compared to primary hepatocytes [48]. However, HepG2 contains a high level of mitochondria and mtDNA and is therefore a good model to investigate mitochondrial toxicity [49]. It should be noted that HepG2 cells as cancer cells have distinct metabolism involving oxidative glutaminolysis (nonexisting in primary noncancerous hepatocytes) and their ability to switch between aerobic glycolysis and and oxidative phosphorylation, thus varying contribution of these two to overall ATP. This is in contrast to primary hepatocytes in which 99\% ATP originates from oxidative phosphorylation. Permeabilization may on one hand equalize these distinctions, but not the different enzyme composition pattern of HepG2 cells versus primary hepatocytes. Limitations in the use of primary human hepatocytes are their limited availability, instability in vitro, and substantial variability if derived from different donors [48].

\section{Conclusion}

LPS decreased mitochondrial membrane potential and cellular ATP content in intact HepG2 cells without impairing basal respiration. However, maximal (stimulated) respiration was decreased in the presence of exogenous substrates (permeabilized cells) in a time-dependent and dose-dependent fashion. In primary hepatocytes, LPS decreased as well as cellular respiration in the presence of exogenous substrates (permeabilized cells) without impairing basal respiration.

Our data confirm the heterogeneous reaction of mitochondrial respiration to LPS.

\section{Conflict of Interests}

The authors declare that there is no conflict of interests regarding the publication of this paper.

\section{Authors' Contribution}

Victor Jeger, Sebastian Brandt, and Francesca Porta all contributed equally to this paper.

\section{Acknowledgments}

The authors thank Sandra Nansoz and Tsilla Sunier for their technical assistance. This study was supported by the Swiss National Science Foundation (Grant no. 32003B_127619). Victor Jeger was supported by MD-PhD scholarship of the Swiss National Science Foundation (no. 133901).

\section{References}

[1] B. Beutler, "Tlr4: central component of the sole mammalian LPS sensor," Current Opinion in Immunology, vol. 12, no. 1, pp. 2026, 2000.

[2] M. P. Fink and M. P. Fink, "Cytopathic hypoxia: Mitochondrial dysfunction as mechanism contributing to organ dysfunction in sepsis," Critical Care Clinics, vol. 17, no. 1, pp. 219-237, 2001.

[3] M. P. Fink, "Bench-to-bedside review: cytopathic hypoxia," Critical Care, vol. 6, no. 6, pp. 491-499, 2002.

[4] M. Singer and D. Brealey, "Mitochondrial dysfunction in sepsis," Biochemical Society Symposium, vol. 66, pp. 149-166, 1999. 
[5] D. Brealey, M. Brand, I. Hargreaves et al., "Association between mitochondrial dysfunction and severity and outcome of septic shock," The Lancet, vol. 360, no. 9328, pp. 219-223, 2002.

[6] J.-L. Vincent, Y. Sakr, C. L. Sprung et al., "Sepsis in European intensive care units: results of the SOAP study," Critical Care Medicine, vol. 34, no. 2, pp. 344-353, 2006.

[7] D. C. Angus, W. T. Linde-Zwirble, J. Lidicker, G. Clermont, J. Carcillo, and M. R. Pinsky, "Epidemiology of severe sepsis in the United States: analysis of incidence, outcome, and associated costs of care," Critical Care Medicine, vol. 29, no. 7, pp. 1303-1310, 2001.

[8] J. A. Russell, J. Singer, G. R. Bernard et al., "Changing pattern of organ dysfunction in early human sepsis is related to mortality," Critical Care Medicine, vol. 28, no. 10, pp. 3405-3411, 2000.

[9] M. P. Callery, T. Kamei, and W. Flye, "Kupffer cell blockade increases mortality during intra-abdominal sepsis despite improving systemic immunity," Archives of Surgery, vol. 125, no. 1, pp. 36-40, 1990.

[10] S. W. Chensue, P. D. Terebuh, D. G. Remick, W. E. Scales, and S. L. Kunkel, "In vivo biologic and immunohistochemical analysis of interleukin- $1 \alpha, \beta$ and tumor necrosis factor during experimental endotoxemia: kinetics, kupffer cell expression, and glucocorticoid effects," The American Journal of Pathology, vol. 138, no. 2, pp. 395-402, 1991.

[11] K. Takeda, T. Kaisho, and S. Akira, “Toll-like receptors," Annual Review of Immunology, vol. 21, pp. 335-376, 2003.

[12] R. L. Kitchens, P.-Y. Wang, and R. S. Munford, "Bacterial lipopolysaccharide can enter monocytes via two CD14-dependent pathways," The Journal of Immunology, vol. 161, no. 10, pp. 5534$5545,1998$.

[13] N. Thieblemont and S. D. Wright, "Transport of bacterial lipopolysaccharide to the Golgi apparatus," The Journal of Experimental Medicine, vol. 190, no. 4, pp. 523-534, 1999.

[14] W. L. Beatty, S. Méresse, P. Gounon et al., "Trafficking of Shigella lipopolysaccharide in polarized intestinal epithelial cells," Journal of Cell Biology, vol. 145, no. 4, pp. 689-698, 1999.

[15] C. Forestier, E. Moreno, J. Pizarro-Cerda, and J.-P. Gorvel, "Lysosomal accumulation and recycling of lipopolysaccharide to the cell surface of murine macrophages, an in vitro and in vivo study," The Journal of Immunology, vol. 162, no. 11, pp. 67846791, 1999.

[16] T. Vasselon, E. Mailman, R. Thieringer, and P. A. Detmers, "Internalization of monomeric lipopolysaccharide occurs after transfer out of cell surface CD14," Journal of Experimental Medicine, vol. 190, no. 4, pp. 509-521, 1999.

[17] V. A. K. Rathinam and K. A. Fitzgerald, "Lipopolysaccharide sensing on the inside," Nature, vol. 501, no. 7466, pp. 173-175, 2013.

[18] N. Kayagaki, M. T. Wong, I. B. Stowe et al., "Noncanonical inflammasome activation by intracellular LPS independent of TLR4," Science, vol. 341, no. 6151, pp. 1246-1249, 2013.

[19] I. Diaz-Laviada, J. Ainaga, M. Teresa Portoles, J. L. Carrascosa, A. M. Muncio, and R. Pagani, "Binding studies and localization of Escherichia coli lipopolysaccharide in cultured hepatocytes by an immunocolloidal-gold technique," The Histochemical Journal, vol. 23, no. 5, pp. 223-228, 1991.

[20] I. Marzo, S. A. Susin, P. X. Petit et al., "Caspases disrupt mitochondrial membrane barrier function," FEBS Letters, vol. 427, no. 2, pp. 198-202, 1998.

[21] R. J. Clem, E. H.-Y. Cheng, C. L. Karp et al., "Modulation of cell death by $\mathrm{Bcl}-\mathrm{x}(\mathrm{L})$ through caspase interaction," Proceedings of the National Academy of Sciences of the United States of America, vol. 95, no. 2, pp. 554-559, 1998.

[22] Q. Sun, W. Gao, P. Loughran et al., "Caspase 1 activation is protective against hepatocyte cell death by up-regulating beclin 1 protein and mitochondrial autophagy in the setting of redox stress," The Journal of Biological Chemistry, vol. 288, no. 22, pp. 15947-15958, 2013.

[23] V. Jeger, S. Djafarzadeh, S. M. Jakob, and J. Takala, "Mitochondrial function in sepsis," European Journal of Clinical Investigation, vol. 43, no. 5, pp. 532-542, 2013.

[24] M. M. Levy, A. Artigas, G. S. Phillips et al., "Outcomes of the Surviving Sepsis Campaign in intensive care units in the USA and Europe: a prospective cohort study," The Lancet Infectious Diseases, vol. 12, no. 12, pp. 919-924, 2012.

[25] K. Fredriksson, U. Flaring, C. Guillet, J. Wernerman, and O. Rooyackers, "Muscle mitochondrial activity increases rapidly after an endotoxin challenge in human volunteers," Acta Anaesthesiologica Scandinavica, vol. 53, no. 3, pp. 299-304, 2009.

[26] K. Fredriksson, F. Hammarqvist, K. Strigård et al., "Derangements in mitochondrial metabolism in intercostal and leg muscle of critically ill patients with sepsis-induced multiple organ failure," The American Journal of Physiology: Endocrinology and Metabolism, vol. 291, no. 5, pp. E1044-E1050, 2006.

[27] S. Portmann, R. Fahrner, A. Lechleiter et al., "Antitumor effect of SIRT1 inhibition in human HCC tumor models in vitro and in vivo," Molecular Cancer Therapeutics, vol. 12, no. 4, pp. 499508, 2013.

[28] F. Rencurel, M. Foretz, M. R. Kaufmann et al., "Stimulation of AMP-activated protein kinase is essential for the induction of drug metabolizing enzymes by phenobarbital in human and mouse liver," Molecular Pharmacology, vol. 70, no. 6, pp. 19251934, 2006.

[29] S. Djafarzadeh, M. Vuda, J. Takala, M. Ochs, and S. M. Jakob, "Toll-like receptor-3-induced mitochondrial dysfunction in cultured human hepatocytes," Mitochondrion, vol. 11, no. 1, pp. 83-88, 2011.

[30] F. Porta, J. Takala, C. Weikert et al., "Effects of prolonged endotoxemia on liver, skeletal muscle and kidney mitochondrial function," Critical Care, vol. 10, no. 4, article R118, 2006.

[31] M. Vuda, L. Brander, R. Schröder, S. M. Jakob, J. Takala, and S. Djafarzadeh, "Effects of catecholamines on hepatic and skeletal muscle mitochondrial respiration after prolonged exposure to faecal peritonitis in pigs," Innate Immunity, vol. 18, no. 2, pp. 217-230, 2012.

[32] H. Steen, J. G. Maring, and D. K. F. Meijer, "Differential effects of metabolic inhibitors on cellular and mitochondrial uptake of organic cations in rat liver," Biochemical Pharmacology, vol. 45, no. 4, pp. 809-818, 1993.

[33] E. H. Carchman, S. Whelan, P. Loughran et al., "Experimental sepsis-induced mitochondrial biogenesis is dependent on autophagy, TLR4, and TLR9 signaling in liver," FASEB Journal, vol. 27, no. 12, pp. 4703-4711, 2013.

[34] M. Růžička, E. Škobisová, A. Dlasková et al., "Recruitment of mitochondrial uncoupling protein UCP2 after lipopolysaccharide induction," The International Journal of Biochemistry and Cell Biology, vol. 37, no. 4, pp. 809-821, 2005.

[35] H. J. Lee, Y. K. Oh, M. Rhee et al., "The role of STAT1/IRF-1 on synergistic ROS production and loss of mitochondrial transmembrane potential during hepatic cell death induced by LPS/ d-GalN," Journal of Molecular Biology, vol. 369, no. 4, pp. 967984, 2007. 
[36] A. G. Testro and K. Visvanathan, "Toll-like receptors and their role in gastrointestinal disease," Journal of Gastroenterology and Hepatology, vol. 24, no. 6, pp. 943-954, 2009.

[37] T. Matsumura, A. Ito, T. Takii, H. Hayashi, and K. Onozaki, "Endotoxin and cytokine regulation of toll-like receptor (TLR) 2 and TLR4 gene expression in murine liver and hepatocytes," Journal of Interferon and Cytokine Research, vol. 20, no. 10, pp. 915-921, 2000.

[38] H. B. He, X. L. Wu, B. Yu et al., "The effect of desacetyluvaricin on the expression of tlr4 and p53 protein in hepg 2.2.15," Hepatitis Monthly, vol. 11, no. 5, pp. 364-367, 2011.

[39] R. Tamura, T. Kanda, F. Imazeki et al., "Hepatitis C virus nonstructural 5A protein inhibits lipopolysaccharide-mediated apoptosis of hepatocytes by decreasing expression of toll-like receptor 4," Journal of Infectious Diseases, vol. 204, no. 5, pp. 793-801, 2011.

[40] S. Akira, S. Uematsu, and O. Takeuchi, "Pathogen recognition and innate immunity," Cell, vol. 124, no. 4, pp. 783-801, 2006.

[41] A. P. West, I. E. Brodsky, C. Rahner et al., "TLR signalling augments macrophage bactericidal activity through mitochondrial ROS," Nature, vol. 472, no. 7344, pp. 476-480, 2011.

[42] B. S. Zuckerbraun, B. Y. Chin, M. Bilban et al., "Carbon monoxide signals via inhibition of cytochrome c oxidase and generation of mitochondrial reactive oxygen species," The FASEB Journal, vol. 21, no. 4, pp. 1099-1106, 2007.

[43] A. McGivney and S. G. Bradley, "Action of bacterial endotoxin and lipid A on mitochondrial enzyme activities of cells in culture and subcellular fractions," Infection and Immunity, vol. 25, no. 2, pp. 664-671, 1979.

[44] F. Porta, J. Takala, C. Weikert, P. Kaufmann, S. Krahenbuhl, and M. S. Jakob, "Effect of endotoxin, dobutamine and dopamine on muscle mitochondrial respiration in vitro," Journal of Endotoxin Research, vol. 12, no. 6, pp. 358-366, 2006.

[45] T. Shibata, Y. Motoi, N. Tanimura, N. Yamakawa, S. Akashitakamura, and K. Miyake, "Intracellular TLR4/MD-2 in macrophages senses Gram-negative bacteria and induces a unique set of LPS-dependent genes," International Immunology, vol. 23, no. 8, pp. 503-510, 2011.

[46] S. Dunzendomfer, H. K. Lee, K. Soldau, and P. S. Tobias, “Tolllike receptor 4 functions intracellularly in human coronary artery endothelial cells: roles of LBP and sCD14 in mediating LPS responses," FASEB Journal, vol. 18, no. 10, pp. 1117-1119, 2004.

[47] J. L. Dixon and H. N. Ginsberg, "Regulation of hepatic secretion of apolipoprotein B-containing lipoproteins: information obtained from cultured liver cells," Journal of Lipid Research, vol. 34, no. 2, pp. 167-179, 1993.

[48] M. T. Donato, A. Lahoz, J. V. Castell, and M. J. Gómez-Lechón, "Cell lines: a tool for in vitro drug metabolism studies," Current Drug Metabolism, vol. 9, no. 1, pp. 1-11, 2008.

[49] D. Höschele, "Cell culture models for the investigation of NRTIinduced mitochondrial toxicity. Relevance for the prediction of clinical toxicity," Toxicology in Vitro, vol. 20, no. 5, pp. 535-546, 2006. 

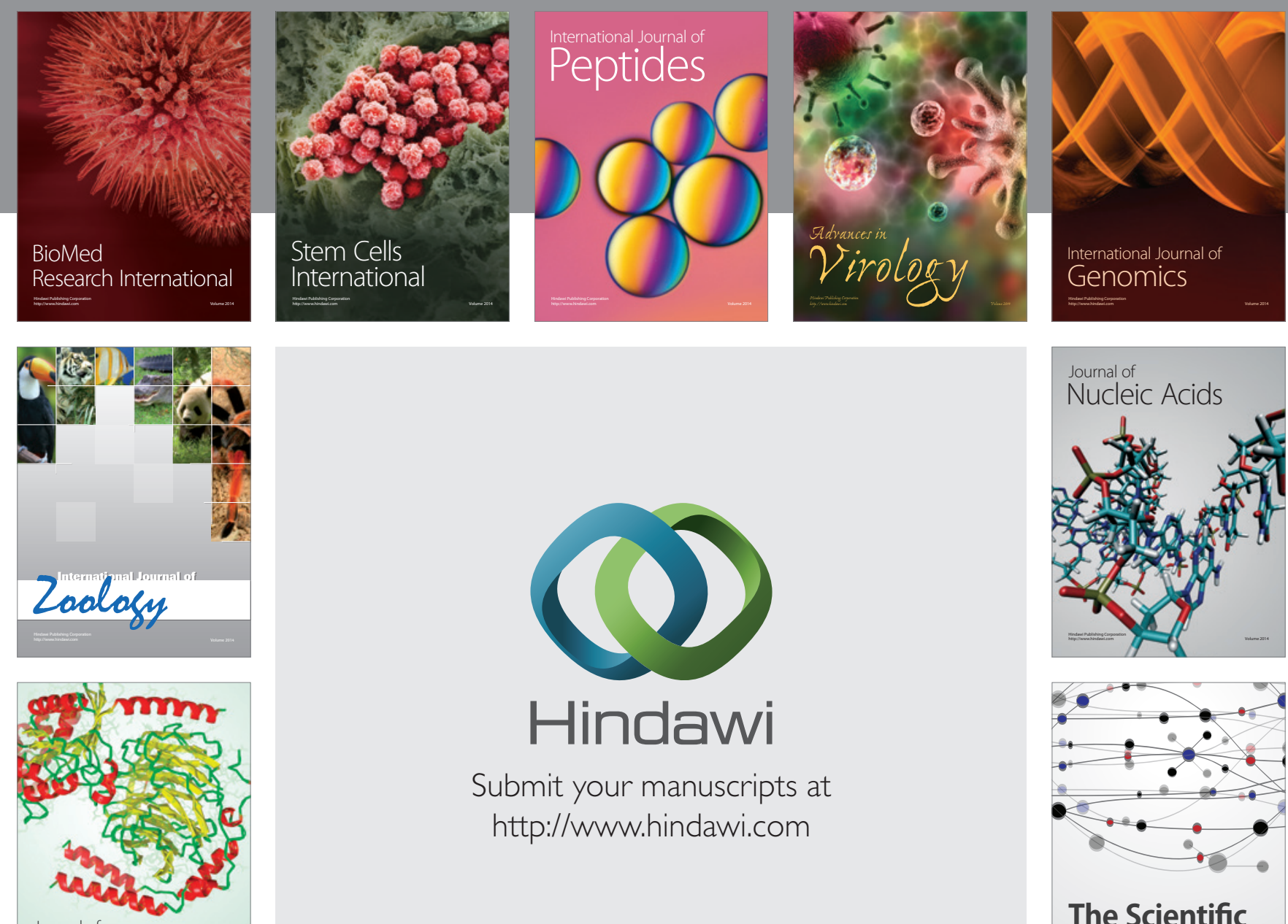

Submit your manuscripts at

http://www.hindawi.com

Journal of
Signal Transduction
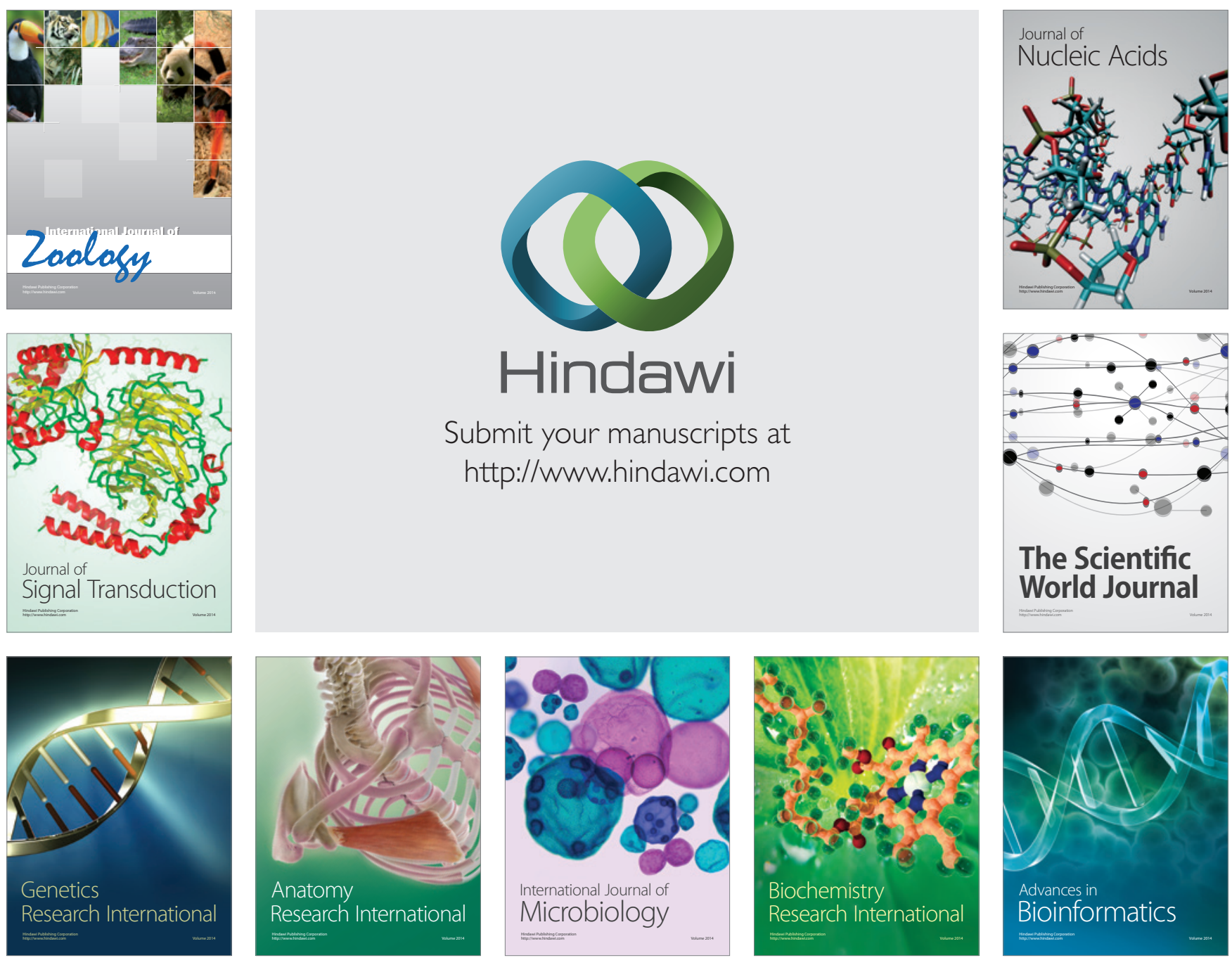

The Scientific World Journal
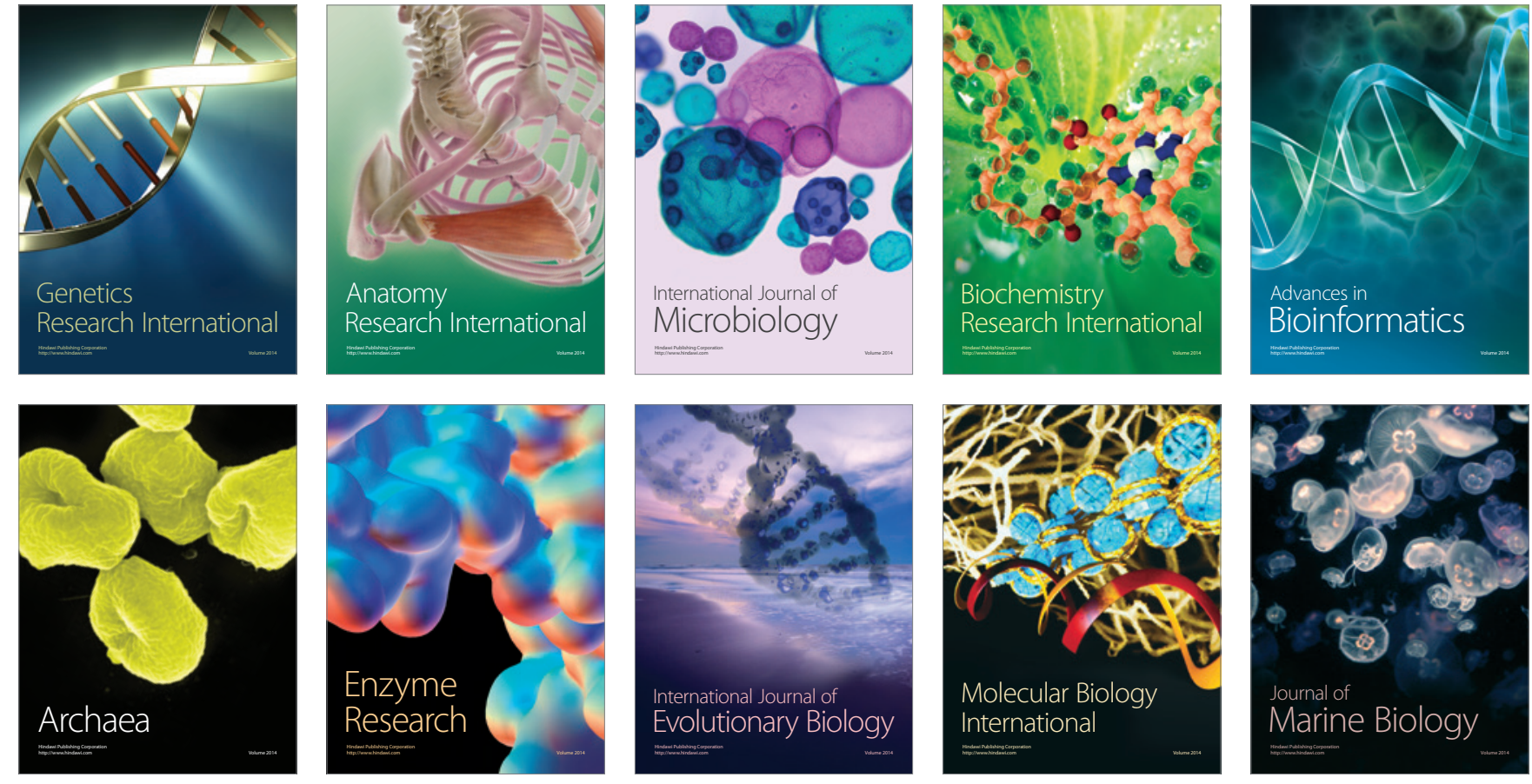